\title{
THE EMOTIONALLY ABUSED WOMAN: AN EXISTENTIAL-PHENOMENOLOGICAL EXPLORATION
}

\author{
KAREN EVE LECOVIN \\ The Union Institute Graduate School \\ and \\ P. SUSAN PENFOLD \\ University of British Columbia
}

\begin{abstract}
This study investigated the meaning of the emotional abuse experience for six women co-researchers, using an existential-phenomenological approach. Their experiences show a number of shared themes. All were emotionally abused in their families of origin and all described similar stages in their reactions to the abuse. All experienced an almost total loss of self in the partnership relationship and all identified the same key components as being critical to their healing process. Many factors appear to contribute to the development of emotional abuse, including cultural norms that do not encourage the nurturing of independence and self-esteem in females.
\end{abstract}

\section{INTRODUCTION}

Growing public concern about emotional abuse is illustrated by attention to emotional as well as physical and sexual abuse of children and adults. Follingstad, Rutledge, Berg. Hause, and Polek (1990) found that emotional abuse (termed "psychological abuse") occurred in $99 \%$ of the 234 cases of physical abuse they studied. They went on to recommend that "future research should investigate emotional abuse patterns in non-battering relationships. ...." The phenomenal success of Women Who Love Too Much (Norwood, 1985) and Men Who Hate Women and the Women Who Love Them (Forward \& Torres, 1986) attests to the growing public awareness of the abuse of women.

This investigation focuses solely on women. It delineates themes and stages of women's experience of emotional abuse by male partners, and the women's eventual departures from the relationships. It defines various themes and experiences common to emotionally abused women. These themes contribute to a definition of emotional abuse.

A review of the literature on emotional abuse highlights the difficulty in defining this phenomenon, its virtual eclipse by the compelling attributes of physical abuse, and the disputes about causation. Emotional abuse touches many aspects of our existence, including legal/advocacy, social, familial, economic, physical, psychological, philosophical and cultural issues (Barnett \& LaViolette. 1993). Its pervasiveness tends to defy encapsulated definition and contributes to its 
trivialization. Nicarthy (1986) states that, "Emotional abuse is sometimes so complex and bewildering it is difficult to name. ... I was still struggling, as were many of the women subjected to emotional abuse, to identify it in specific terms" (p. 285). MacLeod (1987) specifies that psychological violence includes, "Overt or veiled threats and the systematic erosion of the woman's control in the relationship and often all aspects of her life" (p. 19). Engel's more comprehensive definition encompasses control of the victim by domination, verbal assaults, abusive expectations, emotional blackmail, unpredictable responses, constant criticism, character assassination, crazy-making manipulations, constant chaos, and sexual harassment (1990).

Emotional abuse in which one partner systematically attacks the self-esteem of another tends to occur over a period of years. Such abuse, according to Battered Women's Support Services, "Is not just a conflict between two people. It is, rather, a systematic pattern of domination and control. ... The intent is to control women through isolation, pain and fear" (1994). This study makes use of Engel's definition of emotional abuse, but it focuses on women's perceptions of that abuse. As a result of what the women experienced, our definition is perhaps looser than Engel's, but the consistent responses we received suggest a certain order in the chaos and confusion that characterize the experience of emotional abuse.

Only recently has emotional abuse been recognized as an independently destructive factor in relationships (Adaham, 1987; Engel, 1990; Evans, 1992). Psychological and verbal abuse are more common than physical abuse (Willet \& Barnett, 1987), and there are some indications that the lasting damage is more extensive (British Columbia Task Force on Family Violence, 1992). At present, evidence of emotional abuse is papered over by a number of factors including misdiagnosis and victim-blaming by professionals (Herman, 1992; Stark, Flitcraft, \& Frazier, 1979; Brava-Rosewater, 1985). Other camouflaging factors include: victims' lack of awareness of the origin of their suffering (Engel, 1990: Evans, 1992); victims' reluctance to disclose, even to their therapist (Pennebaker \& Susman, 1988); and pressure on the victim to move beyond the trauma (Barnett \& LaViolette, 1993) and stop talking about it (Pennebaker, 1991).

Just as emotional abuse has been difficult to define and recognize in women who have been victims, the causes of such abuse are not clear. Theories of causation centre on the individual, her family of origin, and the patriarchal nature of society. As Hotaling and Sugarman, however, describe it: "The most influential victim precipitant is being female" (1986, p. 119). An over-emphasis on individual responsibility reveals itself in some clinical and psychiatric views of the emotionally abused woman, which label her as "neurotic," "hysteric," and a "hypochondriac" (Stark et al., 1979). Other research emphasizes the victim's family of origin, suggesting that childhood emotional deprivation may lead a woman to choose a man who awakens similar feelings in her. The woman tries to rewrite the seript of her childhood and create a perfect family (Engel, 1990; Forward \& Torres, 1986; Norwood, 1985; Petrie, Giordano, \& Roberts, 1991).

A large body of literature also relates abuse to pervasive male dominance and patriarchal hierarchies (Dobash \& Dobash, 1979; Hoff, 1990; Hotaling \& Sugarman, 1986: Kolbenschlag, 1981; Yllo \& Bograd, 1988). The literature suggests that anyone could get trapped in an abusive relationship (Barnett \& La- 
Violette, 1993). This view contradicts family of origin theories which hypothesize that the woman who was emotionally abused as a child is "a particular type of woman" (Engel, 1990, p. 7). We take the position that while any woman may find herself trapped in an abusive relationship, there are certain recurrent themes in a woman's experiences, including family of origin abuse, which may make staying in an abusive relationship more likely.

\section{METHOD}

We used an existential-phenomenological approach to study the experiences of six women who described themselves as having been involved in long-term emotionally abusive relationships. The women are identified as (A), (B), (D), (E), $(G)$, and $(J)$. Existential-phenomenology is a combination of two philosophical disciplines that together attempt to provide an understanding of the human condition. As Valle and King describe it, existentialism, "Seek[s] to understand the human condition as it manifests itself in our concrete, lived situations." They define phenomenology as "A method which allows us to contact phenomena as we actually live them out and experience them" (1978, pp. 6-7). The methodology of this study may be considered existential-phenomenological because it focuses on the experiences of the women as they tell their own stories, in their own voices.

Existential-phenomenological research describes the experience of the phenomenon being investigated using descriptive techniques. The researcher does not seek to explain, predict, or control the data, but tries to understand the nature of the experience. This research method is consistent with the principles of feminist research in psychology as outlined by Fine and Gordon (1991). The women speak about their experiences in their own words, and we did not try to fit the themes which emerged into previously existing, and possibly patriarchal, paradigms. Ultimately, the women themselves defined the various themes which, we argue, constitute the experience of emotional abuse.

\section{Procedure}

Two in-depth tape-recorded interviews were conducted with six women, ranging in age from 27 to 54 , who described themselves as emotionally abused, according to the criteria set out by Engel (1990, p. 13). They were selected at random. All come from Judeao-Christian backgrounds. Their ethnic origins are Slavic and European, but all are Canadian born. All but one woman has a university education. All six women had left emotionally abusive relationships more than a year earlier, and considered themselves to have undergone some healing. The abusive relationships had lasted from three to 22 years. The women were asked to reflect on their lives before the abuse began, during the years of abuse, and after the abuse was terminated. They were also encouraged to comment on their childhood experiences, and their courtship with the abusing partner.

The interviews were conducted according to the method outlined by Colaizzi (1978, pp. 59-62). We used his "dialogal approach" (1978, p. 69) where the woman's experience is discussed as much as possible without preconceptions on the researcher's part. Open-ended questions were used to elicit data because these questions are less leading. The questions were broad so that the women themselves 
could control a large part of the interview process. They could accurately be described as co-researchers. The goal of this study is to understand the meaning of the women's experiences from the perspective of the women involved. From the transcripts of the taped dialogues, the authors, in conjunction with the women, isolated the themes which were common to the described experiences. Ultimately, the interviews and experiences formulated themselves into an extended definition of emotional abuse.

\section{Analysis}

Each transcript was read several times to uncover the nuances of the experience. We recorded key phrases directly related to the women's experiences on index cards. We then compiled cards with similar meanings or evocations. The next step was to arrange the themes according to whether they tended to occur before, during, or after the emotional abuse experience. This gave three chronological phases which did not have rigid boundaries. Some women encountered different themes simultaneously; some did not. Some perceived them in a different order than they are presented. A theme was only included in this study if it had been experienced by more than three of the women.

The various themes form part of a larger whole, the experience of an emotionally abusive relationship. While certain themes appear to contradict each other, such contradictions reflect the chaos of the abuse experience, in which two distinctly opposed emotions can co-exist. Conversely, some themes appear similar or interchangeable, but they represent different stages in the process of the women's experience, and reflect different depths of emotion. Anger and resentment can occur early on, and reveal a woman's angry reaction as she begins to understand the reality of her situation. Rage, however, reveals a deeper and more unpredictable emotion. Zetlin (1989) noted rage was a common theme among women who are emotionally abused; we found this also to be the case. Anger occurs with recognition of the situation; rage occurs after repeated experiences of defeat or powerlessness. Therefore we have made anger and rage two separate themes.

Transcripts were made of the first interviews along with a typed list of the themes. These were presented to each woman during the second interview for the purpose of validation. In these second interviews, the women tended to develop a more comprehensive view of their situations; several expanded on key points raised in the earlier interviews. The women reported feeling empowered by the interview process. They remarked that they had increased their understanding of the abusive experience. Thirty-seven themes evolved from the examination of the six tran-scripts. Although they were not strictly sequential, the themes could be divided roughly into three phases, beginning, middle, and final. These phases coincide with the development of the abusive relationship from its early stages until the relationship ended. The exact time frame for each phase, however, varied from woman to woman. While it would be impossible to delineate each theme fully in this paper, or to give lengthy and detailed quotations, we have followed some themes with one or two quotes taken directly from the transcripts. 


\section{The beginning phase}

Typical themes identified in this phase included a belief system where no matter how negative the marital relationship between her parents, a woman clung to the belief that she would attain the ideal partnership, and that being in a relationship with a man was intrinsically good. One woman, (G), stated, "I never questioned that he would be there [for me]." These idealized expectations caused the women to want their partners to, in (A)'s words, "Fill me up emotionally ... [be] a companion, a best friend, someone to share all my emotional details." She notes that this was "an unreal expectation."

The women observed that they felt simultaneously needy and lacking in selfesteem. (J) said, "I always felt pretty bad about myself." All the women were vulnerable to male attention and not able to discriminate between positive and negative behaviours. During the early phase of the relationship, the abused woman's lack of a strong personal identity propelled her to focus on her partner without regard for herself. (D) believed that her husband "was the most important person."

As the women discussed their initial involvement in the abusive relationship, they were asked to reflect on their families of origin. Their partnership choices appeared to have been influenced by their families of origin. The behaviour she displayed in her relationship, (D) said, was similar to the way her mother, "Deals with the men in her life." Family of origin involvement seemed stronger during the second set of interviews. The women said that prior to meeting their partners they felt unfulfilled. (A) stated, "My ex-husband ... filled up what I didn't get as a child." Yet, she also said, "He never gave me the love I wanted." (G) said, "When I was 18 and in college, I was longing to meet someone and get married because I wasn't happy as a child ... . and I just kept thinking, 'It's okay, because when I grow up ... I'Il have a happy family." All of the women were convinced they would create a different and more positive family life than their parents'.

At the same time, the women tried to duplicate their families of origin. (A) recalled that, "On some level I was wanting to create a false sort of life like I grew up in my family home." They described their vulnerability and felt emotionally deficient. (G) said, "I was so desperate to have someone love me that $\mathrm{F} d$ do anything." She also commented, "I never really [knew] what he felt for me, not knowing if he loved me or hated me or was indifferent ... I just didn't know how to read what was going on." These feelings began to surface repetitively as themes.

In the course of our research, we noted how intricately these various themes were interwoven and how difficult it was to separate one theme from another. It was as if the confusion and chaos of the abusive relationship was replicated in the internal experience of the women.

\section{The middle phase}

During the middle phase, the women accepted their subservient role. At the same time they felt confused and sad as they realized the relationship was falling short of their dreams. In their efforts to curtail their partners' abusive behaviour and maintain peace at home, the women denied their feelings and censored their behaviour. This deliberate effacing of the self, however, produced no change in the relationship. They felt powerless and impotent and their self-esteem suffered more 
blows. Unable to distance themselves from their husbands' actions and demands, they could not analyze what was happening around them. The women also assumed responsibility for their partners' unhappiness. As (A) believed, "It's a woman's duty to make the family work." Living in turmoil, they felt constantly anxious, and were often engulfed by sudden feelings of apprehension and dread. They were fearful, wary, and alert to any changes in their partners' behaviour. The women lived in a continuous state of heightened awareness and passive submission. (B) said she was "afraid of where to step and not to step." This hypervigilance and lack of trust were common. (E) stated, "I would say to my partner. 'I feel like I'm on eggshells. I never know what to say or do or what your response is going to be towards me.'" The women's inability to discriminate between their partners' behaviours during courtship became a recurring theme.

Some of the women described being subjected to humiliating experiences in front of relatives and friends. (A) related the double messages that she would get from her partner. Her husband brought her "special treats," but when she reached for them, he would say, "You want to keep the weight off." As she noted, "He kept moving the goal posts." These sorts of experiences led to feelings of shame, inadequacy, and isolation. Despite them, most women managed to present a veneer of confidence to the outside world. Keeping up this pretence was emotionally exhausting.

At some level, the women continued to hope that the relationship would change, and felt frustrated, confused, and angry when the changes did not materialize. Nevertheless, they reported continuing to hope. (G) said, "I believed it . .. I just believed that everything would get better." And (E) confirmed, "This is what made me hang on and keep going. I was convinced that eventually it would change."

The women's feelings of powerlessness and frustration in this situation led to an intensification of their anger, often to the level of blinding rage. These rages came without warning, and caused their thought processes to become distorted. Murderous and suicidal impulses arose. Her anger, (A) said, "Over time was turning to more and more rage, where I just wanted to kill the guy." (J) commented, "I think the rage was because I felt powerless to change anything."

At this point, the women became emotionally immobilized, numbed, and deadened. They saw themselves as completely trapped in the relationship, not able to leave their partners because they felt unable to manage on their own. Their state of dependency perpetuated a sense of self-hatred. (E) stated, "I justified his abuse .... I felt I deserved it."

They became totally dependent on the relationship. As a result, the women described feeling isolated, and they withdrew. (B) said, "I felt I was no longer being heard ..., so I stopped sharing [with others]." (A) said, "I just totally withdrew into myself. ... I'd go through the motions of going to functions. I was very isolated in my marriage."

Eventually, the women realized that the destructive nature of the relationship would not change. This turning point is elusive and difficult to place in the chronology of a woman's experience. Even in the eariy stages of a relationship a woman has enough awareness to realize that she needs to assert herself and gain 
some control. It is not until the final phase of her emotionally abusive experience. however, that this awareness becomes the foundation for her actions.

\section{The final phase}

The themes and emotions in this phase show a movement away from the abusive relationship. The women gained an awareness of the dynamics of the relationship and the power and control exercised by their partners over them. At some point, recognition that the abuse would never stop outweighed the notion that the relationship could improve. The women then attempted to regain some control over their lives. Often at this stage they sought counselling, or began seriously to contemplate separation from their abusers. They realized that the anger and abuse that had been directed at them by their partners was not their fault. Even though they recognized the need to end the relationship, however, they maintained a hope and desire that the partner would change. For some, this created an intense dilemma that remained at the forefront of their awareness for a long time.

The themes described in this final phase were interchangeable, as in the other two phases. Some women regained a sense of control. (A) asserted herself by telling her partner that his behaviour toward her was unacceptable. She said, "I needed him not to control and abuse me." Similarly, (B) joined Al-Anon and took responsibility for her own actions. Others sought professional help. (J) said, "I could not have gotten free of his hold on me alone." (A) cultivated friendships, "So I wouldn't be alone going through this hard period."

Disillusioned and devastated by the relationship, some women repeatedly sifted through past scenarios, trying to understand what went wrong. For others, the termination of the relationship ushered in a feeling of liberation and release from constant emotional pain. All the women, however, found that thoughts and feelings about the relationship frequently surfaced as flashbacks. Daily reminders triggered memories. (E) stated, "I constantly have triggers, something will trigger a memory, and I'II ... go back and analyze." (D) commented, "Some nights I dream and wake up sweating because I'm going through something that happened in the marriage."

Memories retained the cognitive and emotional content of the original experience and became powerful intrusions in the woman's life. Some women found that the flashbacks helped them move forward, others complained that they kept them stuck in the same place.

Feelings of guilt and worthlessness surface when a woman leaves an abusive relationship. These feelings endure long after the relationship has ended and even when the woman has gained some insight and understanding of herself and the nature of her relationship. (G) stated, "The way I was loving, thinking that I was loving him so much, wasn't really loving but acts of desperation." The women simultaneously felt guilt and failure. (B). for example, said, "I made the marriage and 1 should be staying. . . . There's a lot of guilt around leaving a marriage." All of the women felt a sense of loss. (G) described her post-relationship existence as "a void." She said, "I felt an emptiness." (E) felt that the loss of her relationship pervaded everything she did afterward. 
The women believed that a large part of themselves died because they had identified so intensely with their abuser. The new life away from the abuser often produces a vacuum which the woman finds too calm. (J) described this feeling as "like being in a noisy city and you move to the country." They reported a tendency to create chaos in subsequent relationships.

\section{DISCUSSION}

The women who participated in this study collaborated with the authors to provide an expanded description of the experience of emotional abuse and the three general phases associated with it. They did this through the discussion of a series of extended and recurring themes. The women unanimously agreed that an emotionally abusive relationship moves through these phases. This suggests that the general themes which they described identify major aspects of the nature of emotionally abusive relationships. The dominant themes conveyed by the women depicted prolonged and devastating anguish.

The women's opinions about, and attempts to understand their experiences, parallelled Engel's descriptions of emotional abuse (1990, p. 13). In describing the first phase of the abusive relationship, the women highlighted their individual failings. They suggested that abuse or deprivation in their family of origin was linked to their choice of partner. As the relationship progressed, they blamed themselves for anything that went wrong, Later, however, they began to attribute some responsibility to their abusers.

While many ingredients may combine to create an emotionally abusive relationship, the road to recovery is long and intricate. As the women demonstrated, recovery does occur, but its extent depends on many factors, including the severity of the abuse and the extent of erosion of the women's identity and self-worth. Many of the women hesitated to leave the abusive relationship because they feared the economic consequences.

Another important aspect to recovery is counselling which validates a woman's experience, helps her to terminate the abuse, ensures her safety and protection, and does not blame her for the abuse. Empowerment and helping to create new support systems is vital. Counselling these women requires good working knowledge of Post Traumatic Stress Disorder (Matsakis, 1992). For some women a support group of abused women may be a powerful adjunct or perhaps more acceptable than individual counselling (Pressman, 1989).

Not all women respond to the termination of the abusive relationship with feelings of relief and a sense of rebirth. Some women simultaneously suffer pangs of grief and self-blame, and repeatedly re-live scenarios from the relationship. Our own experience as therapists suggests that as a woman starts to recover, and is more able to analyze her situation objectively, she needs to become aware of the interaction of many dimensions. These include her role in the family as nurturer, mediator, and emotional organizer. They also include society's prescriptions for men to be in control and the "head of the household"; society's sanction of abuse and intimidation by the powerful, instead of problem solving and co-operation; how patterns and modelling in a family of origin have long-lasting effects; the 
influence of other experiences of exploitation and discrimination; and the role of economic and workplace stresses.

The women's conviction that their vulnerability to emotional abuse began with deprived relationships in their families of origin is an interesting one. Were their experiences, growing up as girl children, any different from the norm? Did lack of warmth and lack of positive reinforcement from parents leave them with low selfesteem and without clear boundaries? What about Eichenbaum and Orbach's (1983) contention that all little girls growing up in our culture feel unmothered because their mother has to accustom them to being second class and their lives directed toward fulfilling others' needs? Could the abused women be reflecting society's tendency to blame individuals and families for stresses and strains generated in our social structures (Penfold, 1989)? These questions led to much dialogue between the authors as we tried to eschew linear and polarized thinking (Lerner, 1988, p. 261). We believe that emotional abuse has a number of intertwined causative factors.

\section{CONCLUSION}

An existential-phenomenological exploration of emotional abuse, in which six women participated, demonstrated 37 themes and identified three phases of an abusive relationship. While further research is needed with a variety of groups of women, this study does suggest some general guidelines for identification and management.

\section{RÉSUMÉ}

Cette étude a examiné le sens de la violence émotive vécue par six femmes co-chercheures selon une approche existentielle-phénoménologique. Leurs expériences comprennent plusicurs caractéristiques communes. Toutes les femmes furent victimes de violence familiale et toutes ont décrit des étapes similaires dans leurs réactions face à la violence. Toute ont vécu une importante perte d'identité dans leur relation avec un partenaire intime et toutes ont identifié les mêmes composantes fondamentales comme responsables de leur processus de guérison. Plusieurs facteurs semblent contribuer au développement de la violence émotive, y compris les normes culturelles qui n'encouragent pas la valorisation de l'autonomie et de l'estime de soi chez les femmes.

\section{REFERENCES}

Adahan, M. (1987). APS: Abusive Personality Syndrome. The Jewish Press Magazine (pp. M30-M34). New York.

Barnett, O.W., \& LaViolette, A.D. (1993). It could happen to anyone: Why battered women stay. Beverly Hills, CA: Sage.

Battered Women's Support Services. (1994). Violence against women in British Columbia: A fact sheet. Battered Women's Support Services Fact Sheet \#4, Vancouver, BC.

Brava-Rosewater, L. (1985). Schizophrenic, borderline or battered? In L. Brava-Rosewater \& L. Walker (Eds.), Handbook of feminist therapy (pp, 215-225). New York: Springer.

British Columbia Task Force on Family Violence. (1992), Is anyone listening? Victoria: Ministry of Women's Equality. 
Colaizzi, P.F. (1978). Psychological research as the phenomenologist views it. In R.S. Valle \& M. King (Eds.), Existential-phenomenological altematives for psychology (pp. 59-62). New York: Oxford University Press.

Dobash, R., \& Dobash, E.R. (1979). Violence against wives: A case against the patriarchy. New York: Free Press.

Engel, B. (1990). The emotionally abused woman: Overcoming destructive pattems and reclaiming yourself. New York: Ballantine Books.

Eichenbaum, L., \& Orbach, S. (1983). Understanding women. New York: Basic Books.

Evans, P. (1992). The verbally abusive relationship: How to recognize it and how to respond. Holbrook, MA: Bob Adams.

Fine, M., \& Gordon, S.M. (1991). Effacing the center and the margins: Life at the intersection of psychology and feminism. Feminism \& Psychology, I(1), 19-27.

Follingstad, D.R., Rutledge, L.L., Berg, B.K., Hause, E.S., \& Polek, D.S. (1990). The role of emotional abuse in physically abusive relationships. Joumal of Family Violence, S(2), $107-119$.

Forward, S., \& Torres, J. (1986). Men who hate women and the women who love them. New York: Bantam Books.

Herman, J.L. (1992). Trauma and recovery. New York: Basic Books.

Hoff, L.A. (1990), Battered women as survivors. London \& New York: Routledge.

Hotaling, G.T., \& Sugarman, D.B. (1986). An analysis of risk markers in husband to wife violence: The current state of knowledge. Violence and Victims, I(2), 118-120.

Kolbenschlag, M. (1981). Kiss sleeping beauty good-bye; Breaking the spell of feminine myths and models. New York: Bantam Books.

Lerner, H.G. (1988), Women in therapy. North Vale, NJ: Jason Aranson.

MacLeod, L. (1987). Battered but not beaten: Preventing wife battering in Canada, Ottawa: Canadian Advisory Council on the Status of Women.

Matsakis, A. (1992), I can't get over it: A handbook for trauma survivors. Oakland, CA: New Harbinger Publications.

Nicarthy, G. (1986). Getting free. Seattle, WA: Seal Press.

Norwood, R. (1985), Women who love too much: When you keep wishing and hoping he'll change. New York: St. Martin's Press.

Penfold, P.S. (1989), Family therapy: Critique from a feminist perspective. Canadian Joumal of Psychiatry, 34, 311-315.

Pennebaker, J.W. (1991). Inhibitions as the linchpin of health. In H.S. Friedman (Ed.), Hostility, coping and health (pp, 127-140). Washington, DC: American Prychological Association.

Pennebaker, J.W., \& Susman, J.R. (1988), Disclosure of traumas and psychosomatic process. Social Siress and Medicine, 26, 327-332.

Petrie, J., Giordano, J.H., \& Roberts, C.S. (1991). Characteristics of women who love too much. Adjilia, 7(1), 7-20.

Pressman, B. (1989). Wife-abused couples: The need for comprehensive theoretical perspectives and integrated treatment models. Joumal of Feminist Family Therapy, I(1), 23-43.

Stark, E., Flitcraft, A., \& Frazier, W. (1979). Medicine and patriarchal violence; The social construction of a private event. Intemational Joumal of Health Sciences, 9, 461-493.

Valle, R.S., \& King, M. (1978). Existential-phenomenological altematives for psychology. New York: Oxford University Press.

Willet, S.L., \& Barnett, O.W. (1987). Doing gender. Gender and Sociefy, 1(1), 125-151.

Yllo, K., \& Bograd, M. (Eds.). (1988), Feminist perspectives on wife abuse. Beverly Hills, CA: Sage.

Zetlin, P.A. (1989). A proposal for a new diagnostic category: Abuse disorder. Joumal of Feminist Family Therapy, 1(4), 67-84. 